\title{
Seasonal variations in exacerbations and deaths in patients with COPD during the TIOSPIR $^{\circledR}$ trial
}

This article was published in the following Dove Press journal: International Journal of COPD

\author{
Robert A Wise' \\ Peter MA Calverley ${ }^{2}$ \\ Kerstine Carter ${ }^{3}$ \\ Emmanuelle Clerisme- \\ Beaty ${ }^{4}$ \\ Norbert Metzdorf ${ }^{5}$ \\ Antonio Anzueto ${ }^{6}$ \\ 'Division of Pulmonary and \\ Critical Care Medicine, Johns \\ Hopkins University School of \\ Medicine, Baltimore, MD, USA; \\ ${ }^{2}$ Respiratory Medicine, University \\ Hospital Aintree, Liverpool, UK; \\ ${ }^{3}$ Biostatistics, Boehringer Ingelheim \\ Pharmaceuticals, Inc., Ridgefield, \\ CT, USA $;{ }^{4}$ Clinical Development and \\ Medical Affairs, Boehringer Ingelheim \\ Pharmaceuticals, Inc., Ridgefield, \\ CT, USA; ${ }^{5}$ Clinical Development and \\ Medical Affairs, Boehringer Ingelheim \\ Pharma GmbH \& Co KG, Ingelheim, \\ Germany; ${ }^{6}$ Department of Pulmonary \\ Diseases and Critical Care Medicine, \\ University of Texas Health Science \\ Center and South Texas Veterans \\ Health Care System, San Antonio, \\ TX, USA
}

Background: Although COPD exacerbations are known to occur more frequently in winter, there is little information on hospitalizations and cause-specific mortality. This study aimed to examine seasonal variations in mortality and exacerbations in patients with COPD during the TIOtropium Safety and Performance In Respimat ${ }^{\circledR}$ (TIOSPIR ${ }^{\circledR}$ ) trial.

Patients and methods: TIOSPIR was a large-scale, multicenter trial, which assessed the safety and efficacy of tiotropium delivered via HandiHaler ${ }^{\circledR}$ (18 $\mu$ g once daily) or Respimat ${ }^{\circledR}$ Soft $\operatorname{Mist}^{\mathrm{TM}}$ ( 2.5 or $5 \mu \mathrm{g}$ once daily) inhaler in patients with COPD. Patients were aged $\geq 40$ years, with a smoking history $\geq 10$ pack-years, and post-bronchodilator forced expiratory volume in 1 second $\leq 70 \%$ and forced expiratory volume in 1 second/forced vital capacity $\leq 0.70$. COPD exacerbations and deaths were monitored throughout the trial. The data were pooled to examine seasonal patterns. Southern hemisphere data were shifted by 6 months to align with northern hemisphere seasons.

Results: TIOSPIR was conducted in 43 northern $(n=15,968)$ and 7 southern $(n=1,148)$ hemisphere $(n=1,148)$ countries. The median duration of treatment was 835 days, with a mean follow-up of 2.3 years. Among 19,494 exacerbations, there were clear seasonal differences (winter, 6,646 [34.1\%]; spring, 4,515 [23.2\%]; summer, 3,198 [16.4\%]; autumn, 5,135 [26.3\%]). Exacerbations peaked in early winter (December in the northern hemisphere and June in the southern hemisphere), respiratory hospitalizations in midwinter, and respiratory deaths in early spring. Conclusion: Although winter poses a 2-fold hazard for COPD exacerbations vs summer, respiratory deaths peak in early spring. These data suggest that seasonal intensification of preventive treatments may impact COPD morbidity and mortality.

Trial registration number: NCT01126437.

Keywords: TIOSPIR, tiotropium, HandiHaler, Respimat Soft Mist inhaler, seasonality, preventive treatment, exacerbations

\section{Plain language summary}

In this retrospective substudy, we analyzed data from the large-scale, multicenter TIOSPIR clinical trial to study seasonal patterns in the numbers and severity of COPD symptom "flareups", cause-specific deaths, and major adverse cardiac events in over 17,000 patients with COPD residing in 50 countries. The study was conducted in both the northern and southern hemispheres, and the southern hemisphere data were shifted by 6 months to align with the northern hemisphere seasons. The data collected confirm the results of COPD symptom "flare-ups" noted from other large clinical trials and provide new data on seasonal variation in cardiovascular and respiratory cause-specific death rates. Winter was associated with a 2 -fold increase in COPD symptom severity compared with summer; however, the peak of respiratory-related deaths occurred in early spring, suggesting that recurrent COPD "flare-ups" or subsequent pneumonia accounts for peak respiratory death rates. Seasonal intensification of preventive therapy may reduce both the severity of COPD symptoms and death rates.
Correspondence: Robert A Wise Division of Pulmonary and Critical Care Medicine, Johns Hopkins University School of Medicine, Johns Hopkins Asthma and Allergy Center, 550I Hopkins Bayview Circle, Baltimore, MD 21224, USA

Tel + I 4105500545

$\mathrm{Fax}+\mathrm{I} 4105502612$

Email rwise@jhmi.edu
International Journal of COPD 2018:13 605-616

(c) (1) (8) ( 2018 Wise et al. This work is published and licensed by Dove Medical Press Limited. The full terms of this license are avalable at https://www.dovepress.com/terms.ph cc. hereby accept the Terms. Non-commerial uses of the work are permitted without any further permision from Dove Medical Press Limited, provided the work is properly attributed. For permission for commercial use of this work, please see paragraphs 4.2 and 5 of our Terms (htpps://www.dovepress. com/terms.php). 


\section{Introduction}

In the general population, seasonal differences in mortality have been observed, with more people dying in winter. ${ }^{1-4}$ Seasonal variations have been shown for several clinical conditions, where symptoms and mortality increase in winter, for example, cardiovascular disease, ${ }^{2,5-7}$ influenza and pneumonia, ${ }^{8-10}$ and pulmonary embolism. ${ }^{11-13}$ COPD exacerbations,${ }^{14}$ COPD-related hospitalizations, ${ }^{15}$ community-acquired pneumonia, ${ }^{16}$ and respiratory mortality are also most common in winter, ${ }^{14,17-20}$ and may be influenced by increased incidence of infections. Acute exacerbations of COPD etiology vary with season, and the rises in incidence in winter may be driven by increased airway infections. ${ }^{21}$

Understanding the nature and magnitude of seasonal differences for COPD morbidity is important as it can: 1) guide efficient health resource allocation; 2) suggest seasonal strategies to prevent exacerbations in high-risk patients; and 3) assist in efficient planning of clinical trials studying COPD exacerbations.

Seasonal differences in the occurrence of COPD exacerbations have been found in several clinical trials. ${ }^{18,19}$ These differences were most evident in the northern hemisphere, but prospectively collected data on seasonal variations in hospitalization, cause-specific mortality, and major adverse cardiac events (MACE) have yet to be reported.

Analyzing the largest long-term trial in COPD (TIOtropium Safety and Performance In Respimat [TIOSPIR ${ }^{\circledR}$ ]) reported to date ${ }^{22,23}$ provided a unique opportunity to expand our understanding of seasonal variations in COPD morbidity and mortality. TIOSPIR was conducted worldwide in the northern and southern hemispheres, involving 1,202 centers in 50 countries. It had an almost complete follow-up vital status rate $(99.7 \%$ of randomized patients); exacerbation events were monitored and verified, underlying causes of death adjudicated, and MACE data collected. Compared to other clinical studies, TIOSPIR used liberal inclusion and exclusion criteria, especially regarding concomitant cardiovascular diseases. Thus, the TIOSPIR data allowed us to study the effect of seasonality on the numbers and severity of exacerbations, cause-specific mortality, and MACE in a broadly representative COPD population of sufficient size to examine less-frequent events and provide estimates of the magnitude of any seasonal effect on important COPD outcomes.

\section{Patients and methods Study design}

The main trial design and rationale have been described previously. ${ }^{22}$ Briefly, TIOSPIR was a randomized, multicenter, double-blind, parallel-group, event-driven trial designed to assess safety and efficacy of tiotropium delivered once daily via HandiHaler ${ }^{\circledR}(18 \mu \mathrm{g})$ or Respimat ${ }^{\circledR}(2.5$ or $5 \mu \mathrm{g})$ inhaler in COPD patients.

TIOSPIR was conducted in compliance with the Declaration of Helsinki. The study protocol and procedures were approved by the local institutional review boards and ethics committees for participating centers (Table S1). All patients gave written informed consent prior to participation in the study.

\section{Study participants}

Patients were outpatients, aged $\geq 40$ years, who were either current or ex-smokers with $\geq 10$ pack-years of smoking history. Patients had a COPD diagnosis, post-bronchodilator forced expiratory volume in 1 second $\leq 70 \%$ predicted, and post-bronchodilator forced expiratory volume in 1 second/ forced vital capacity $\leq 70 \%$. Complete inclusion/exclusion criteria are provided in Table S2. Maintenance respiratory medications and medications for comorbid conditions were permitted, with the exception that non-study drug inhaled anticholinergics were not permitted.

\section{Assessments}

The co-primary end points for the main trial were times to all-cause death and first COPD exacerbation. Outcome measures evaluated for this analysis included number and incidence of moderate-to-severe COPD exacerbations, severe COPD exacerbations, cause-specific deaths, and MACE. MACE included fatal events in the Medical Dictionary for Regulatory Activities V.16.0 system organ classes of cardiac and vascular disorders; outcome events (serious and nonserious) of myocardial infarction, stroke, and transient ischemic attack; and preferred terms of sudden death, cardiac death, and sudden cardiac death. Sudden death was death occurring $>1$ to $<24$ hours from a patient being last seen alive without an evident deteriorating medical condition. Sudden cardiac death was a marked change in a patient's clinical state resulting in death within 1 hour of onset in the absence of noncardiac causes.

Exacerbations were defined as increase or new onset of $\geq 2$ lower respiratory symptoms (breath shortness, sputum production, purulent sputum, cough, wheezing, and chest tightness) that were COPD related, lasted $\geq 3$ days, and required a treatment change (antibiotics and/or systemic steroids prescription, or new respiratory medication). Exacerbations were classified as mild (requiring new maintenance bronchodilator only), moderate (requiring antibiotics or systemic steroids without hospitalization), and severe (requiring hospitalization). Exacerbation onset was defined as the first 
recorded symptom, and exacerbation end was based on a site-investigator report. When there were $<7$ days between the end of one exacerbation and the beginning of another, they were combined into a single exacerbation (if the first exacerbation was pretreatment, it was not combined).

An independent Mortality Adjudication Committee blinded to treatment reviewed the case report forms, medical documents, and witness reports and adjudicated the primary underlying cause of death using standardized criteria. ${ }^{24,25}$ Generally, primary death cause was attributed to the underlying clinical condition for which the patient initially presented for treatment and not to the immediate cause of death (further details are provided in the Supplementary Appendix of Wise et $\mathrm{al}^{23}$ ). Respiratory deaths were defined as those in the "Respiratory, thoracic, and mediastinal disorders" system organ classes, along with deaths from respiratory tract infections.

All patients, including those who discontinued the study drug early, were followed for vital status until the end of the trial. Patients discontinuing early had a 30-day follow-up, and thereafter, were followed for vital status every 12 weeks until the end of the trial.

\section{Statistical analyses}

Deaths (all-cause and cause-specific) and COPD exacerbations were described numerically and by incidence rates using descriptive statistics.

Death rates were calculated from the vital status set (full follow-up period) and exacerbation rates from the treated set (on-treatment period), accounting for time at risk and treatment duration, respectively. Incidence rates were based on 1,000 patient-months' exposure.

To study seasonal patterns, data from the treatment groups were pooled. ${ }^{23}$ To compare northern and southern hemisphere data, southern hemisphere data were shifted by 6 months (eg, for the first winter month, December in the northern hemisphere aligned to June in the southern hemisphere).

\section{Results}

\section{Baseline demographics and characteristics}

Of 20,313 patients screened for TIOSPIR, 17,183 were randomized and 17,135 (99.7\%) received $\geq 1$ dose of study medication (vital status data set). The treated data set comprised 17,116 patients, since 19 were excluded for data irregularities. In the northern hemisphere, 15,987 patients were in the vital status data set and 15,968 in the treated data set, while in the southern hemisphere the vital status and treated data sets both had 1,148 patients. Study centers $(\mathrm{N}=1,202)$ were located in 43 northern and 7 southern hemisphere countries
(Table 1). The median duration of treatment was 835 days (range 1-1,027 days), with a mean follow-up of 2.3 years.

Patient baseline and clinical characteristics were relatively well balanced between the hemispheres (Table 1). The only notable differences between the northern and southern hemispheres were that in the northern hemisphere a higher proportion of patients were current smokers (39.0\%

Table I Baseline demographic and clinical characteristics of patients from the northern and southern hemispheres

\begin{tabular}{|c|c|c|}
\hline Variable & $\begin{array}{l}\text { Northern } \\
\text { hemisphere }^{a} \\
(n=15,968)\end{array}$ & $\begin{array}{l}\text { Southern } \\
\text { hemisphere }^{b} \\
(n=I, \mid 148)\end{array}$ \\
\hline \multicolumn{3}{|l|}{ Sex } \\
\hline Male & II,426 (7I.6) & $811(70.6)$ \\
\hline Female & $4,542(28.4)$ & $337(29.4)$ \\
\hline \multicolumn{3}{|l|}{ Race } \\
\hline White & $12,939(8 \mid .0)$ & $\mathrm{I}, 024(89.2)$ \\
\hline Black & $178(1.1)$ & $78(6.8)$ \\
\hline Asian & $2,383(14.9)$ & $45(3.9)$ \\
\hline Missing & $468(2.9)^{c}$ & $\mathrm{I}(0.1)^{\mathrm{d}}$ \\
\hline Age, years & $64.9 \pm 9.1$ & $66.1 \pm 9.0$ \\
\hline \multicolumn{3}{|l|}{ Age class, years } \\
\hline$<60$ & $4,476(28.0)$ & $287(25.0)$ \\
\hline 60 to $<70$ & $6,259(39.2)$ & $443(38.6)$ \\
\hline$\geq 70$ & $5,233(32.8)$ & $418(36.4)$ \\
\hline Body mass index, $\mathrm{kg} / \mathrm{m}^{2}$ & $26.3 \pm 5.7$ & $25.6 \pm 5.2$ \\
\hline \multicolumn{3}{|l|}{ Body mass index class } \\
\hline Underweight $\left(<18.5 \mathrm{~kg} / \mathrm{m}^{2}\right)$ & $1,013(6.3)$ & $85(7.4)$ \\
\hline Normal $\left(18.5\right.$ to $\left.<25 \mathrm{~kg} / \mathrm{m}^{2}\right)$ & $6,210(38.9)$ & $476(4 I .5)$ \\
\hline Pre obese $\left(25\right.$ to $\left.<30 \mathrm{~kg} / \mathrm{m}^{2}\right)$ & $5,140(32.2)$ & $369(32.1)$ \\
\hline Obese $\left(\geq 30 \mathrm{~kg} / \mathrm{m}^{2}\right)$ & $3,605(22.6)$ & $218(19.0)$ \\
\hline COPD duration, years & $7.4 \pm 6.2^{\mathrm{e}}$ & $7.7 \pm 5.9$ \\
\hline \multicolumn{3}{|l|}{ Smokers } \\
\hline Never smoked & $3(0.0)$ & $0(0.0)$ \\
\hline Ex-smoker & $9,745(61.0)$ & $849(74.0)$ \\
\hline Current smoker & $6,220(39.0)$ & $299(26.0)$ \\
\hline Smoking history, pack-years & $43.3 \pm 24.3$ & $50.1 \pm 29.2$ \\
\hline \multicolumn{3}{|l|}{ Pulmonary medication } \\
\hline ICS (but not LABA) & $\mathrm{I}, 034(6.5)$ & $197(\mid 7.2)$ \\
\hline LABA (but not ICS) & $1,628(10.2)$ & $78(6.8)$ \\
\hline Both ICS and LABA & $8,239(51.6)$ & $633(55.1)$ \\
\hline Neither ICS nor LABA & $5,067(31.7)$ & $240(20.9)$ \\
\hline Systolic blood pressure, $\mathrm{mmHg}$ & $131.2 \pm 15.3^{f}$ & $127.9 \pm 15.4$ \\
\hline Diastolic blood pressure, $\mathrm{mmHg}$ & $78.1 \pm 9.6^{f}$ & $77.8 \pm 9.8$ \\
\hline Pulse rate, bpm & $76.8 \pm 11.7^{f}$ & $76.1 \pm 11.1$ \\
\hline \multicolumn{3}{|l|}{ Region } \\
\hline Europe, Africa, Australia, New Zealand & $9,197(57.6)$ & $442(38.5)$ \\
\hline Latin America & $294(1.8)$ & $706(6 I .5)$ \\
\hline North America & $4,121(25.8)$ & $0(0.0)$ \\
\hline Asia & $2,356(14.8)$ & $0(0.0)$ \\
\hline
\end{tabular}

Notes: Data are expressed as mean \pm SD or as number (\%) patients. ${ }^{a}$ Forty-three northern hemisphere countries: Austria, Belgium, Bulgaria, Canada, P.R. China, Croatia, Denmark, Finland, France, Georgia, Germany, Greece, Guatemala, Hungary, India, Ireland, Israel, Italy, Latvia, Lithuania, Malaysia, Mexico, the Netherlands, Norway, Panamá, Philippines, Poland, Portugal, Republic of Korea, Romania, Russia, Serbia, Slovakia, Spain, Sweden, Switzerland, Taiwan R.O.C., Thailand, Tunisia, Turkey, Ukraine, UK, and USA. bSeven southern hemisphere countries: Argentina, Australia, Brazil, Colombia, New Zealand, Peru, and South Africa. 'This category includes 468 patients from France where race cannot be collected. ${ }^{\circ}$ One patient from Peru whose race was determined to be Mestizo. ${ }^{e} n=15,965$ patients. ${ }^{f} n=15,959$ patients. Abbreviations: ICS, inhaled corticosteroids; LABA, long-acting beta-agonist. 
vs $26.0 \%$ ), a lower proportion were taking only inhaled corticosteroids (6.5\% vs $17.2 \%)$, and a higher proportion were taking neither inhaled corticosteroids nor long-acting beta-agonists (31.7\% vs $20.9 \%)$.

In the northern hemisphere, the mean $\pm \mathrm{SD}$ exposure time to treatment was $731 \pm 257$ days and the mean observation time was $842 \pm 142$ days. In the southern hemisphere these were slightly lower, with a mean exposure of $683 \pm 241$ days and a mean observation time of $778 \pm 167$ days. These equated to overall observation times of 36,781 patient-years in the northern and 2,440 patient-years in the southern hemisphere. In both hemispheres, the proportion of patients with $<1$ year of treatment was around $13 \%$, so bias by season of recruitment between the hemispheres is unlikely.

\section{Exacerbations}

Overall, 8,342 (48.7\%) patients had $\geq 1$ exacerbation and $2,506(14.6 \%)$ had $\geq 1$ severe exacerbation. Among the total 19,494 exacerbations, the highest number $(6,646$ [34.1\%]) occurred in winter and the lowest (3,198 [16.4\%]) in summer. Severe exacerbations (3,816 [19.6\% of all exacerbations]) followed the same pattern, with the highest frequency in winter (1,349 [35.4\%]) and the lowest in summer (611 [16.0\%]). Mild exacerbations were rare, with $97.9 \%(19,093)$ of all exacerbations being moderate to severe.

For each hemisphere, the numbers of exacerbations and patients experiencing exacerbations are given in Table 2.

Table 2 Number of exacerbations and deaths for patients from the northern and southern hemispheres

\begin{tabular}{|c|c|c|}
\hline Variable & $\begin{array}{l}\text { Northern } \\
\text { hemisphere } \\
(n=I 5,968)\end{array}$ & $\begin{array}{l}\text { Southern } \\
\text { hemisphere } \\
(n=I, \mid 48)\end{array}$ \\
\hline $\begin{array}{l}\text { Total COPD exacerbations requiring } \\
\text { treatment, } n\end{array}$ & 17,742 & $\mathrm{I}, 752$ \\
\hline Patients with $\geq$ I exacerbation, $n(\%)$ & $7,660(48.0)$ & $682(59.4)$ \\
\hline $\begin{array}{l}\text { Total moderate-to-severe COPD } \\
\text { exacerbations, } \mathrm{n}\end{array}$ & 17,365 & $\mathrm{I}, 728$ \\
\hline $\begin{array}{l}\text { Patients with } \geq \text { I moderate-to-severe } \\
\text { exacerbation, } \mathrm{n}(\%)\end{array}$ & $7,520(47.1)$ & $675(58.8)$ \\
\hline $\begin{array}{l}\text { Total severe COPD exacerbations } \\
\text { requiring hospitalization }\end{array}$ & 3,563 & 253 \\
\hline $\begin{array}{l}\text { Patients with } \geq \text { I severe exacerbation } \\
\text { requiring hospitalization, } \mathrm{n}(\%)\end{array}$ & $2,336(14.6)$ & $170(\mid 4.8)$ \\
\hline \multicolumn{3}{|l|}{ Deaths, n (\%) } \\
\hline All-cause & $1,169(7.3)$ & $133(11.6)$ \\
\hline MACE & 299 & 34 \\
\hline Neoplasms & 284 & 21 \\
\hline Respiratory & 393 & 53 \\
\hline Other & 193 & 25 \\
\hline
\end{tabular}

Abbreviation: MACE, major adverse cardiac event.
The proportion of patients in the northern hemisphere who experienced $\geq 1$ exacerbation requiring treatment was lower than in the southern hemisphere ( $48.0 \%$ vs $59.4 \%$ ), whereas the proportions of patients experiencing severe exacerbations requiring hospitalization were similar for the two hemispheres (14.6\% vs $14.8 \%)$.

Figure 1 illustrates overall variations in exacerbations by month, adjusted for hemisphere. Overall, the number of exacerbations was highest in early winter and lowest in midsummer; hospitalized severe exacerbations were delayed by 1 month. Severe exacerbations peaked in midwinter and were lowest in late summer.

In the northern hemisphere, winter accounted for $34.6 \%(6,147 / 17,742)$ and summer accounted for $15.8 \%$ $(2,807 / 17,742)$ of all exacerbations. This difference was not as strong in the southern hemisphere, with $28.5 \%(499 / 1,752)$ of exacerbations in winter and $22.3 \%(391 / 1,752)$ in summer. In the northern hemisphere, $35.9 \%(1,280 / 3,563)$ of all severe exacerbations occurred in winter and $15.4 \%(547 / 3,563)$ in summer, whereas in the southern hemisphere, the proportions were similar for winter $(27.3 \%$ [69/253]) and summer (25.3\% [64/253]).

Mean incidence of exacerbations for the northern hemisphere was 1.65 -fold higher in winter than in summer (53.6 vs 32.5 per 1,000 patient-months), whereas in the southern hemisphere, it was 1.56 -fold higher ( 83.0 vs 53.1 per 1,000 patient-months). Similar differences in incidence were found for all severity categories of exacerbation, with winter rates $\sim 2.0$-fold greater in the winter peak than the summer nadir (Figure 1E; Table S3). Seasonal differences occurred during all three trial years, indicating that the results were not the consequence of a single severe winter (Figures S1 and $\underline{\mathrm{S}}$ ).

\section{All-cause deaths}

Within the vital status observation period, $7.6 \%(1,302 / 17,135)$ of patients died $-7.3 \%(1,169 / 15,987)$ in the northern and $11.6 \%(133 / 1,148)$ in the southern hemisphere. Overall, deaths were 1.6 times more frequent in winter $(32.6 \%$ [424/1,302]) than summer $(20.5 \%$ [267/1,302]).

The mean death rate (deaths per month as a percentage of total deaths during the study) and the incidence of all-cause deaths in the northern hemisphere were greatest in winter, peaking in midwinter and were lowest in early summer (Figure 2A and B, respectively). In the northern hemisphere, $33.6 \%(393 / 1,169)$ of all-cause deaths occurred in winter and $20.0 \%(234 / 1,169)$ in summer. In the southern hemisphere, a seasonal difference was not apparent for all-cause deaths, with the lowest mean value recorded in mid-spring and the 

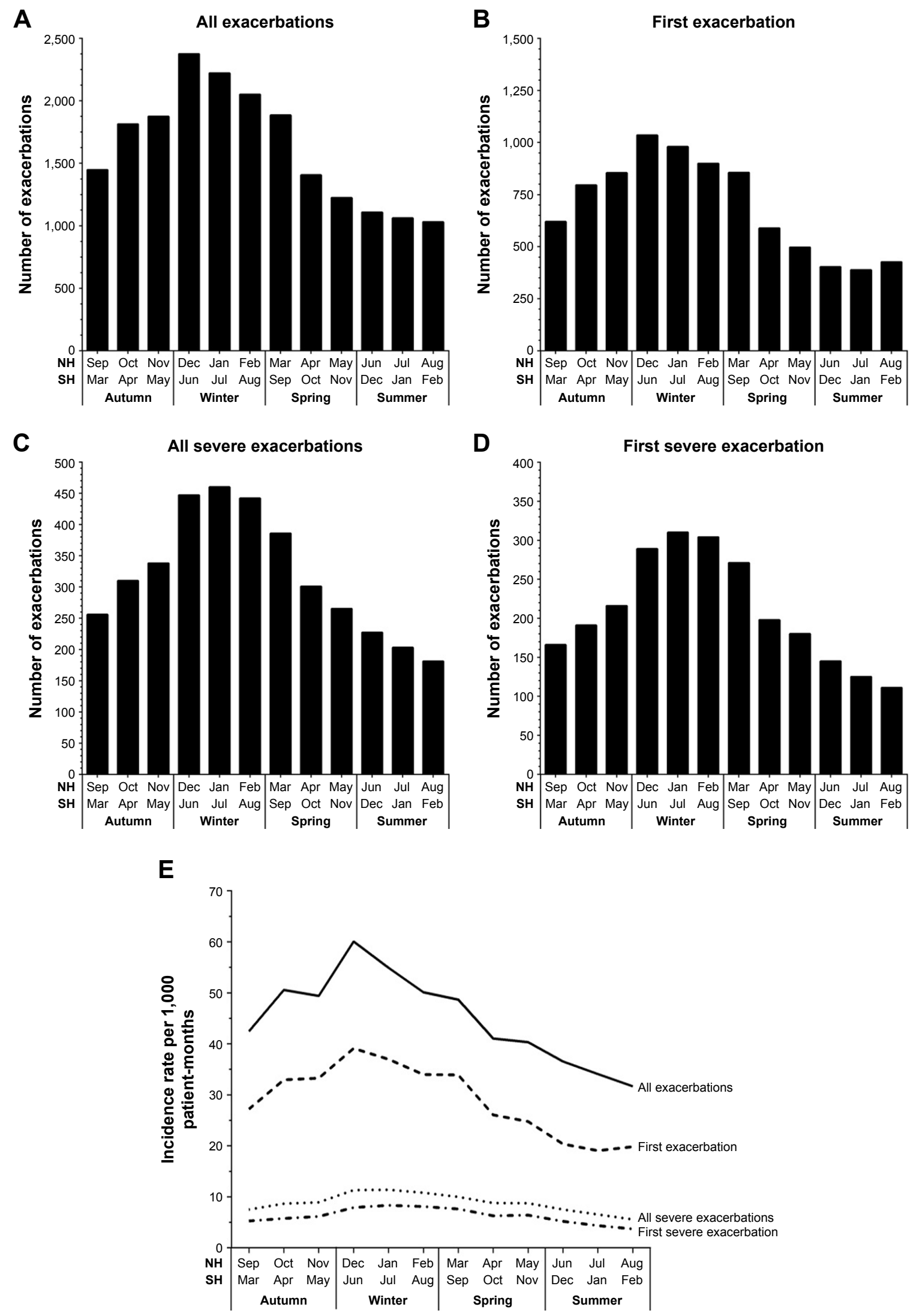

Figure I Numbers of exacerbations and incidence rates per I,000 patient-months of exposure adjusted by hemisphere.

Note: (A) Number of all exacerbations, (B) occurrence of first exacerbation, (C) number of all severe exacerbations, (D) occurrence of first severe exacerbation, and (E) exacerbation incidence rates.

Abbreviations: $\mathrm{NH}$, northern hemisphere; $\mathrm{SH}$, southern hemisphere. 
highest in late spring (Figure 2C and D); 23.3\% (31/133) of all deaths occurred in winter and $24.8 \%$ (33/133) in summer. In the northern hemisphere, the mean incidence of all-cause deaths was 3.10 per 1,000 patient-months in winter and 2.41 per 1,000 patient-months in summer; equivalent values for the southern hemisphere were 4.69 and 4.10 per 1,000 patient-months, respectively.

In the data set adjusted for hemisphere, a seasonal mortality difference was apparent, with the mean proportion and incidence of deaths peaking in midwinter (Figure $2 \mathrm{E}$ and $\mathrm{F}$, respectively). The lowest proportion of deaths occurred in early summer and the lowest incidence was in early autumn. Data for individual months in each year are provided in Figure S3.

A

Northern hemisphere

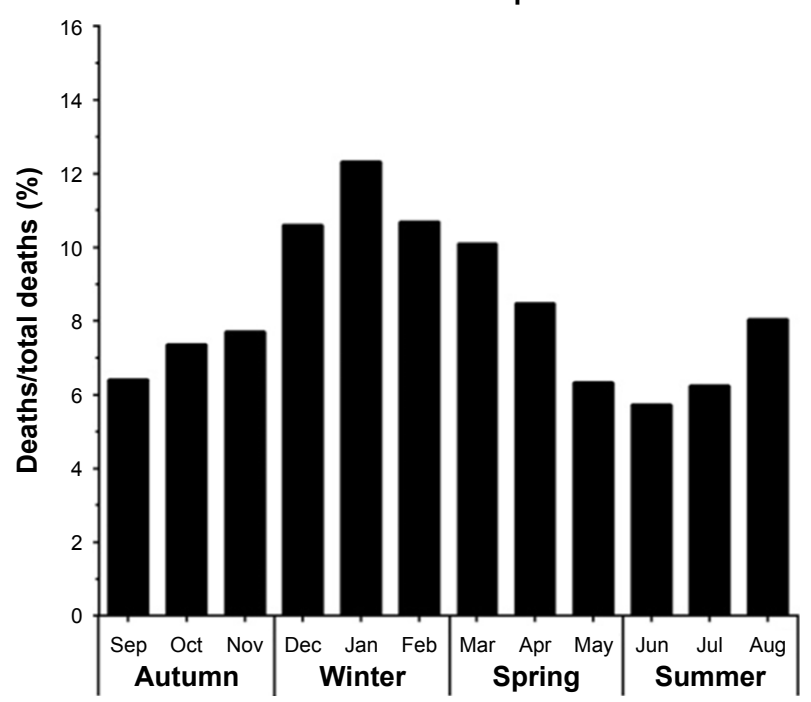

C

Southern hemisphere

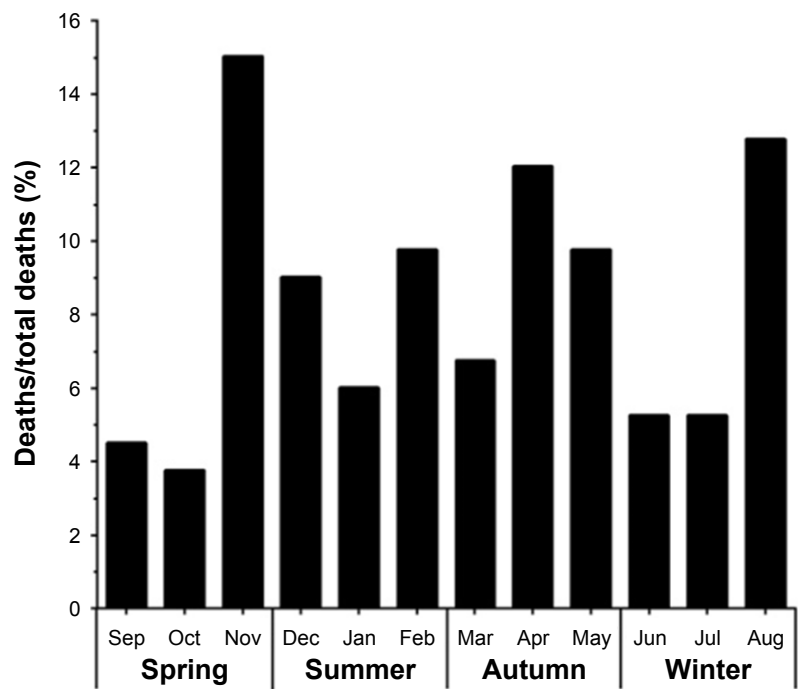

\section{Cause-specific deaths}

The number of deaths and the incidence rate per 1,000 patient-months of exposure for cause-specific deaths (MACE, respiratory, neoplasms, and other causes) are presented in Figure 3. Overall, the most common cause of death was respiratory $(34.3 \%, 0.99$ per 1,000 patient-months $)$, followed by MACE $(25.6 \%, 0.77$ per 1,000 patient-months $)$ and neoplasms (23.4\%, 0.72 per 1,000 patient-months); other causes accounted for $16.7 \%$ (0.61 per 1,000 patient-months). As a proportion of all respiratory deaths, $33.0 \%$ occurred in winter and $18.2 \%$ in summer. Respiratory deaths and incidence of respiratory deaths showed a marked seasonal pattern, peaking in early spring and reaching a nadir in midsummer. Although the number and incidence of deaths related to MACE peaked

B

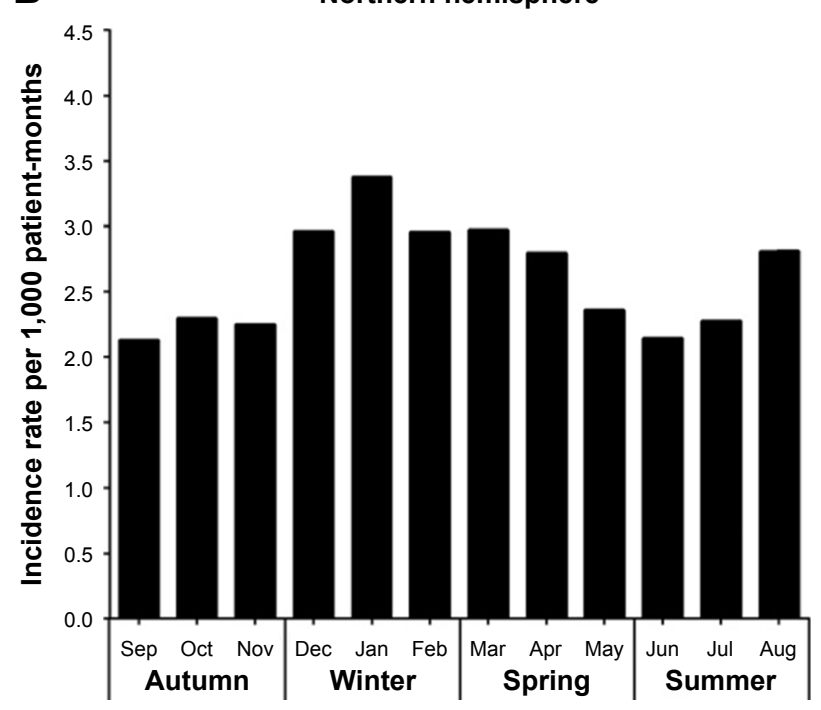

D

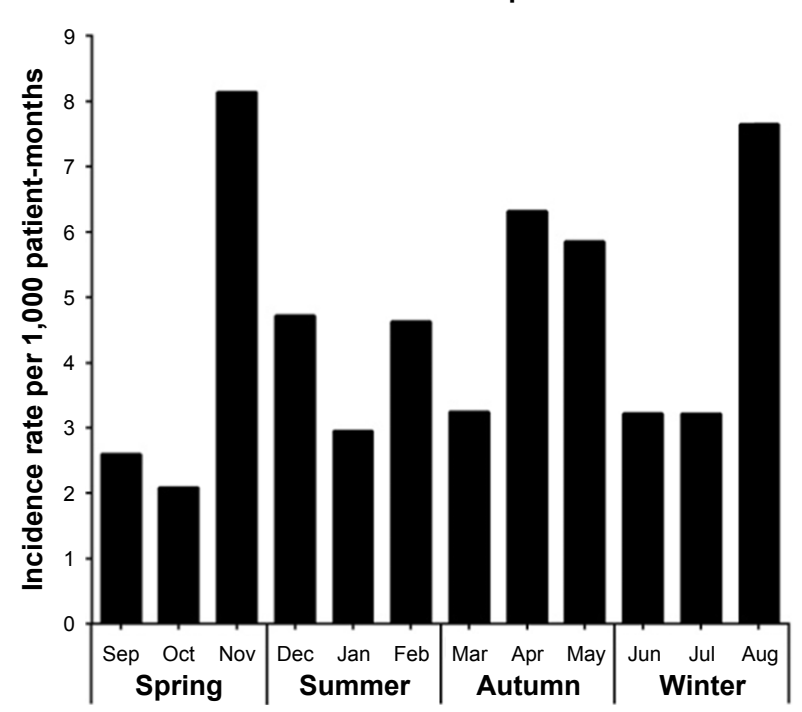

Figure 2 (Continued) 

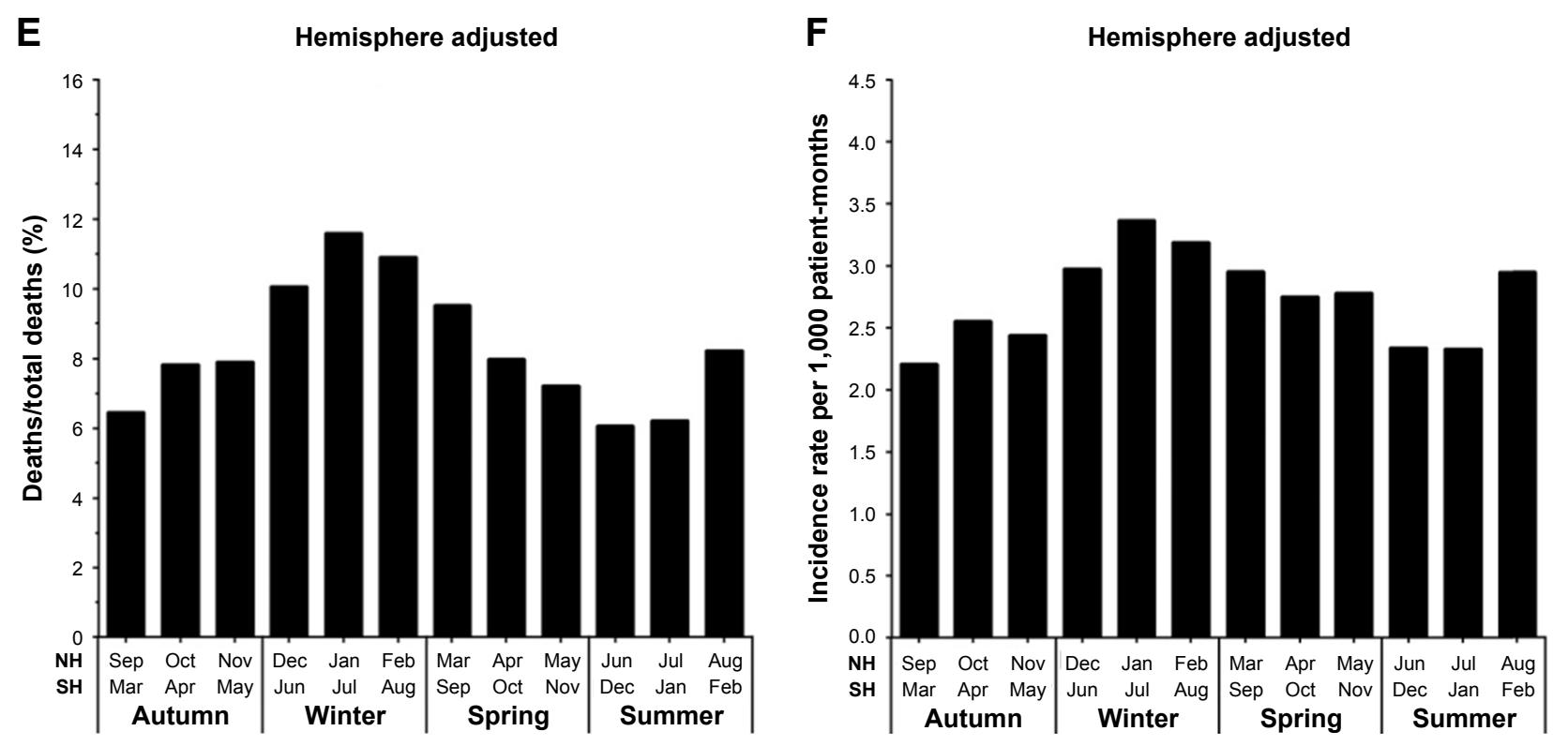

Figure 2 Mean frequency of all-cause deaths (per month as a percentage of the total deaths occurring over the study) and incidence rates of all-cause deaths per I,000 patient-months of exposure.

Note: (A) Northern hemisphere: percentage of deaths, (B) northern hemisphere: incidence rate, (C) southern hemisphere: percentage of deaths, (D) southern hemisphere: incidence rate, $(\mathbf{E})$ hemisphere adjusted percentage of deaths, and $(\mathbf{F})$ hemisphere adjusted incidence rate.

Abbreviations: $\mathrm{NH}$, northern hemisphere; $\mathrm{SH}$, southern hemisphere.

in early winter and reached a nadir in early summer, a seasonal effect was not as pronounced as for respiratory deaths. The number of deaths related to neoplasms and other causes also peaked in winter (early and midwinter, respectively), but seasonality was not pronounced.

\section{Discussion}

Our analysis shows marked seasonal variation in COPD exacerbations, hospitalization, and mortality. These results

A

MACE

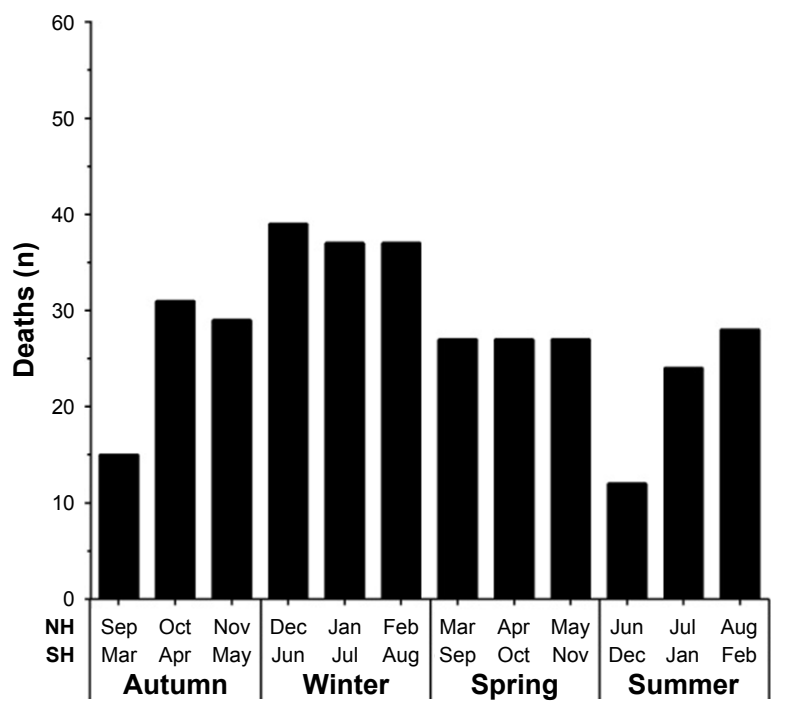

confirm the results of exacerbations noted from analyses of other studies ${ }^{15,16,18,19,21}$ and extend the findings to hospitalization for exacerbations and respiratory mortality. Of interest, in the northern hemisphere, the peak for exacerbations is early winter, followed by the peak for hospitalizations in midwinter and for respiratory deaths in early spring. The reason that seasonal differences for these events are not aligned is not clear. We speculate that milder exacerbations in early winter may provide the substrate for later, more
B

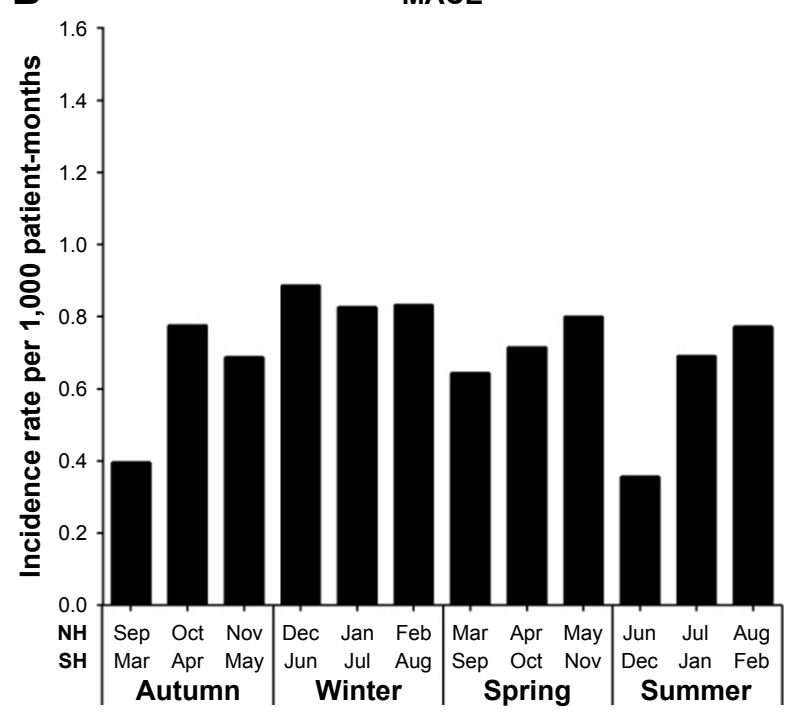

Figure 3 (Continued) 

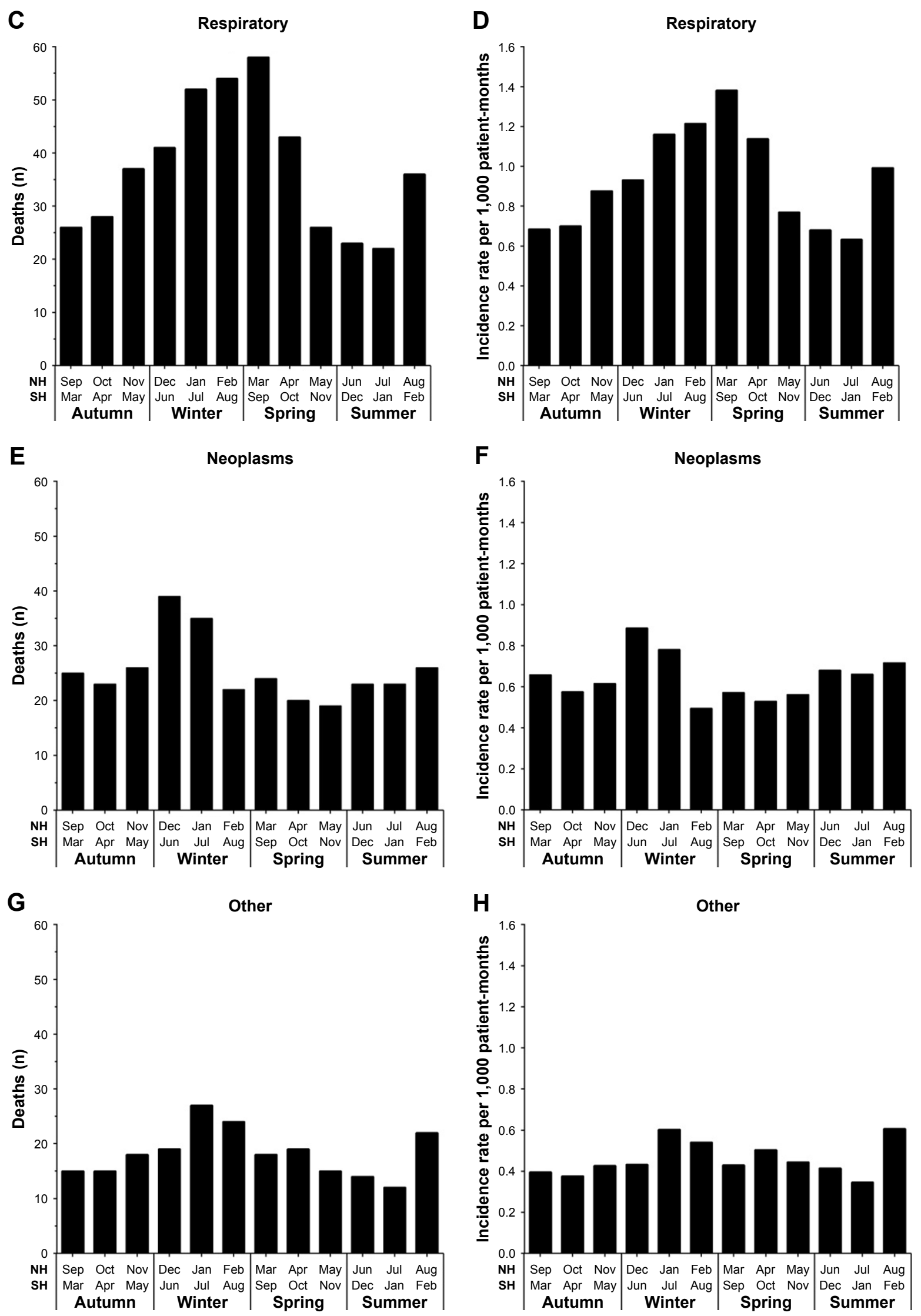

Figure 3 Mean numbers and incidence rates per I,000 patient-months of exposure for cause-specific deaths adjusted for hemisphere.

Note: (A) Number of MACE-related deaths, (B) incidence rate of MACE-related deaths, $(\mathbf{C})$ number of respiratory-related deaths, (D) incidence rate of respiratory-related

deaths, (E) number of neoplasm-related deaths, $(\mathbf{F})$ incidence rate of neoplasm-related deaths, $(\mathbf{G})$ number of other-related deaths, $(\mathbf{H})$ incidence rate of other-related deaths. Abbreviations: MACE, major adverse cardiac event; $\mathrm{NH}$, northern hemisphere; $\mathrm{SH}$, southern hemisphere. 
severe, exacerbations and that these events are the substrate for subsequent mortality. In this regard, it has been shown that COPD exacerbations tend to be clustered and occur with increasing frequency over time. ${ }^{26,27}$ Moreover, our results are consistent with the finding of Suissa et $\mathrm{al}^{27}$ who report that mortality peaks in the 8 weeks after a severe COPD exacerbation.

We also compared seasonal variations in the northern and southern hemispheres. In the northern hemisphere, more than twice as many COPD exacerbations occurred in winter than in summer (representing $34.6 \%$ and $15.8 \%$, respectively, of all exacerbations). In the southern hemisphere, there was a $27.6 \%$ increase in exacerbations in winter vs summer, with $28.5 \%$ of all exacerbations occurring in winter and $22.3 \%$ in summer. This disparity may reflect differences in health care systems impacting time to patient presentation and admission or, since most of the southern hemisphere countries are near the equator, there may have been fewer seasonal variations in weather in these mostly tropical countries compared with those in the northern hemisphere; for example, Colombia and Brazil are equatorial and, therefore, may lack seasons. It is also possible that tropical regions are subject to different types of infections or other exposures that are not present in the northern hemisphere.

Two other large multinational trials, Toward a Revolution in COPD Health (TORCH) $)^{18}$ and Prevention of Exacerbations with Tiotropium in COPD (POET-COPD), ${ }^{19}$ also examined seasonal variations in deaths and exacerbations in COPD. A comparison of the characteristics and results of these trials together with those of TIOSPIR is provided in Table S4.

Our findings from TIOSPIR are somewhat different from those of $\mathrm{TORCH},{ }^{18}$ a global clinical trial involving 6,112 patients in 42 countries (northern region, $n=4,849$; southern region, $n=622$; and tropics, $n=641$ ). In TORCH, seasonal exacerbation patterns were seen in both southern and northern regions, peaking in winter and reaching a nadir in summer, whereas the tropical region showed no seasonal patterns. Based on the percentage of patients with exacerbations, there was a 1.8-fold increase in exacerbations in winter compared with summer in the northern region and a 1.7-fold increase in the southern region. In our analysis, we did not separate out the tropical region, which may account for the different findings.

The POET-COPD trial ${ }^{19}$ was conducted only in the northern hemisphere and included 7,376 COPD patients, of whom 2,691 reported exacerbations. Exacerbation rates in POET-COPD showed a seasonal pattern, peaking in winter, with a mean monthly exacerbation rate of 7.63 exacerbations per 100 patient-months, which was 2.16 -fold higher than the mean summer rate of 3.53 exacerbations per 100 patientmonths. In TIOSPIR, the mean monthly exacerbation rate for the northern hemisphere was 1.65-fold higher in winter than in summer, with exacerbation rates per 100 patient-months of 5.36 and 3.25 for winter and summer, respectively. Greater seasonality and higher event rates in POET-COPD likely reflected the different enrollment criteria for that trial, which sought out patients with high exacerbation risk.

In TIOSPIR, the proportion of all exacerbations requiring hospitalization was $19.6 \%$, which is remarkably similar to the overall figure of $20 \%$ reported by TORCH. ${ }^{18}$ In POET$\mathrm{COPD},{ }^{19}$ the proportions of all exacerbations that were severe were similar for winter and summer (15.8\% vs $17.3 \%)$; our data for the northern hemisphere are similar, with the proportions of all exacerbations that were severe being $20.8 \%$ for winter and $19.5 \%$ for summer. Thus, it does not appear that increased hospitalizations and mortality in winter are caused by a shift in the severity of exacerbations, but are due to increase in the overall number of events.

In TIOSPIR, in the northern hemisphere, $33.6 \%$ of all deaths occurred in winter and $20.0 \%$ in summer. These findings are similar to those of $\mathrm{TORCH},{ }^{18}$ where $29 \%$ of deaths occurred in winter and $22 \%$ in summer, and of POETCOPD,${ }^{19}$ where $34.5 \%$ of deaths occurred in winter and $13.4 \%$ in summer. In TIOSPIR, in the southern hemisphere, a strong seasonal difference was not apparent, with $23.3 \%$ of all deaths occurring in winter and $24.8 \%$ in summer; in TORCH, in the southern region, $37 \%$ of all deaths occurred in winter and $14 \%$ in summer. In TIOSPIR, in the northern hemisphere, the mean incidence rate of all deaths was 3.10 per 1,000 patient-months for winter, which is higher than in POET-COPD, that is, 2.28 per 1,000 patient-months. The TIOSPIR summer death rate of 2.41 per 1,000 patientmonths was also substantially higher than that of POETCOPD (0.88 per 1,000 patient-months). It seems paradoxical that POET-COPD had a higher exacerbation rate, yet lower death rate, compared with TIOSPIR. We speculate that the lower death rates in POET-COPD were due to a combination of lower mean patient age ( $63 \pm 9$ years) compared with TIOSPIR ( $65 \pm 9$ years) and differences in follow-up of 1 vs 2-3 years.

In TIOSPIR, the most common cause of death was respiratory $(34.3 \%, 0.99$ per 1,000 patient-months $)$, which was lower than that reported by $\mathrm{TORCH}^{18}$ for COPD-related deaths (41\%). This difference may be due to the presence of a placebo group in TORCH, whereas all patients in TIOSPIR were provided with maintenance therapy. In TIOSPIR, numbers and incidence rates for respiratory-related deaths showed marked seasonality, peaking in early spring and 
reaching a nadir in midsummer. Of all respiratory deaths, $33.0 \%$ occurred in winter and $18.2 \%$ in summer; these figures are similar to those reported by TORCH for the northern region (34\% and 20\%, respectively), but not for the southern region (55\% and $8 \%$, respectively). In TIOSPIR, although the number and incidence of MACE-related deaths peaked in early winter and reached a nadir in early summer, a seasonal effect was not as evident as with respiratory deaths. MACErelated deaths, which included sudden deaths, also showed a peak in early winter and a nadir in summer, but the seasonal difference was not as pronounced as for respiratory mortality, which, along with showing a peak in early spring, also demonstrated a second peak in late summer. The cause of this late summer peak is not known; however, it may reflect higher levels of air pollutants, warmer temperatures, or cyclical variation in aeroallergens or respiratory viral infections.

The study's strengths are that it reports seasonality data from a large-scale multicenter trial spanning the northern and southern hemispheres, including 17,116 patients who reported 19,494 exacerbations. Vital status follow-up was high (99.7\% of randomized patients), and causes of deaths were adjudicated to a primary cause by an independent Mortality Adjudication Committee, rather than via death certificates, which may underestimate respiratory deaths. ${ }^{28}$ MACE was included as a secondary outcome and was monitored and classified prospectively according to predefined criteria. In contrast to trials that enroll patients at high risk for exacerbation, the inclusion and exclusion criteria were designed to include a broad COPD population, reflecting patients that physicians encounter in daily practice. ${ }^{29}$

The study has some limitations. Although generally, patients with comorbidities, including those with history of cardiac disorders, were included in the trial, those with unstable cardiovascular conditions or moderate-to-severe renal impairment were excluded. The diagnosis of COPD exacerbation was made based on clinical grounds; however, we cannot exclude the possibility that other conditions, such as decompensated heart failure or pulmonary embolism, may have contributed to the respiratory decompensation events. All patients were on maintenance therapy for COPD with $\geq 1$ long-acting bronchodilator during the trial, which may have reduced the overall exacerbation rate compared with the general COPD population. ${ }^{30}$ Data on influenza and pneumococcal immunization were not included as part of the trial, so we cannot determine if these measures altered the winter peak of respiratory illness and deaths. Seasonal variability to COPD exacerbations may reflect different etiologies, such as exposure to air pollution, allergens, viral infections, or bacterial infections. However, we are unable to determine, from this data set, whether this is the case. Finally, because the trial was dominated by data from the northern hemisphere (93.7\% of all data), and we did not classify the sites by weather patterns, our findings regarding lack of seasonality in the southern hemisphere must be interpreted with some caution. The allocation of countries to the northern and southern hemispheres was based on their relationship to the equator; Brazil and Colombia cross the equator, but were included in the southern hemisphere. Almagro et al ${ }^{15}$ found that mean temperatures and COPD-related hospitalization are closely and independently related. Within each hemisphere, there are regional variations in seasonal temperature changes, both within and between countries; in our study, the groupings required to give the study enough power to identify an effect preclude the detailed analysis of temperature differences.

Our data raise a number of issues. First, the striking increase in winter morbidity and mortality suggests that physicians, health care systems, and policymakers could have a greater impact on the major complications of COPD by focusing on preventive measures before and during winter. Measures such as crowd avoidance, hand hygiene, and covering coughs could be stressed as part of individual COPD action plans, in conjunction with autumn influenza immunization campaigns. Second, staffing and facility resource allocation should take into account the 2-fold increases in COPD illness during winter. Third, our findings stress the need for a full year's data to assess the effects of policy and procedural interventions aimed at reducing COPD exacerbations and hospitalization rates; otherwise, seasonal differences may be interpreted as effects of these interventions. Fourth, clinical research aimed at evaluating or treating COPD exacerbations can leverage the striking seasonal variation to conduct more efficient research during winter. Finally, individual physicians may choose to initiate or intensify treatments aimed at reducing exacerbations in high-risk patients during autumn and winter. Our data suggest that focused application of relatively simple measures to prevent early winter exacerbations might have an impact on subsequent hospitalizations and death. ${ }^{31}$

\section{Conclusion}

Patients and clinicians should be fully aware of the increased risks of COPD exacerbations and deaths in winter, to enable appropriate management strategies to be implemented. Clinical trials focusing on COPD exacerbations would be most efficiently conducted during winter. 


\section{Acknowledgments}

This work was supported by Boehringer Ingelheim Pharmaceuticals, Inc. (BIPI). BIPI was given the opportunity to review the manuscript for medical and scientific accuracy as well as intellectual property considerations. The authors received no direct compensation related to the development of the manuscript. Writing and editorial support was provided by Jane M Gilbert BSc CMPP of Envision Scientific Solutions, which was contracted and funded by BIPI. An abstract of this article was presented as an oral presentation at Chest 2014, October 25-30, 2014, Austin, TX, USA, and the abstract was published in Chest. 2014;146(4, Suppl

2):66A.

\section{Author contributions}

The authors meet the criteria for authorship as recommended by the International Committee of Medical Journal Editors (ICMJE). RAW was the coordinating investigator for the TIOSPIR trial. PMAC and AA were members of the trial steering committee. KC was the co-trial statistician. EC-B contributed to the conduct of the trial. Conception and design: RAW, PMAC, NM, and AA. Acquisition, analysis, and interpretation of data: RAW, PMAC, KC, EC-B, NM, and AA. Drafting and revision of the manuscript: RAW, PMAC, $\mathrm{KC}, \mathrm{EC}-\mathrm{B}, \mathrm{NM}$, and AA. All authors contributed to the intellectual content of the manuscript, reviewed drafts of the manuscript, and approved the manuscript version submitted for publication.

\section{Disclosure}

RAW reports personal fees and grants from Boehringer Ingelheim during the conduct of the study. He reports personal fees from AstraZeneca, Boehringer Ingelheim, ContraFect, GlaxoSmithKline, Janssen, Merck, Novartis, Pfizer, Pulmonx, Roche, Spiration, Sunovion, Teva, Theravance, Verona, and Vertex; and grants from AstraZeneca, Boehringer Ingelheim, GlaxoSmithKline, and Pearl Therapeutics outside the submitted work. PMAC reports grants and personal fees from GlaxoSmithKline and Takeda; personal fees from AstraZeneca, Boehringer Ingelheim, Novartis, Zambon, and Recipharm; and non-financial support from Boehringer Ingelheim outside the submitted work. KC and EC-B are employees of Boehringer Ingelheim Pharmaceuticals, Inc. NM is an employee of Boehringer Ingelheim Pharma GmbH \& Co KG. AA reports grants and personal fees from GlaxoSmithKline, and personal fees from AstraZeneca, Boehringer Ingelheim, and Novartis outside the submitted work. The authors report no other conflicts of interest in this work.

\section{References}

1. Wilkinson P, Pattenden S, Armstrong B, et al. Vulnerability to winter mortality in elderly people in Britain: population based study. BMJ. 2004;329(7467):647.

2. Marti-Soler H, Gonseth S, Gubelmann C, et al. Seasonal variation of overall and cardiovascular mortality: a study in 19 countries from different geographic locations. PLoS One. 2014;9(11):e113500.

3. Davie GS, Baker MG, Hales S, Carlin JB. Trends and determinants of excess winter mortality in New Zealand: 1980 to 2000. BMC Public Health. 2007;7:263.

4. Healy JD. Excess winter mortality in Europe: a cross country analysis identifying key risk factors. J Epidemiol Community Health. 2003; 57(10):784-789.

5. Rumana N, Kita Y, Turin TC, et al. Seasonal pattern of incidence and case fatality of acute myocardial infarction in a Japanese population (from the Takashima AMI Registry, 1988 to 2003). Am J Cardiol. 2008;102(10):1307-1311.

6. Spencer FA, Goldberg RJ, Becker RC, Gore JM. Seasonal distribution of acute myocardial infarction in the second National Registry of Myocardial Infarction. J Am Coll Cardiol. 1998;31(6):1226-1233.

7. Marti-Soler H, Gubelmann C, Aeschbacher S, et al. Seasonality of cardiovascular risk factors: an analysis including over 230000 participants in 15 countries. Heart. 2014;100(19):1517-1523.

8. Lieberman D, Porath A. Seasonal variation in community-acquired pneumonia. Eur Respir J. 1996;9(12):2630-2634.

9. Lin HC, Lin CC, Chen CS, Lin HC. Seasonality of pneumonia admissions and its association with climate: an eight-year nationwide population-based study. Chronobiol Int. 2009;26(8):1647-1659.

10. Mahoney A, Polk RE. Seasonal trends in hospitalized patients with pneumonia. $P \&$ T. 2003;28(7):477-479.

11. Dentali F, Ageno W, Rancan E, et al. Seasonal and monthly variability in the incidence of venous thromboembolism. A systematic review and a metaanalysis of the literature. Thromb Haemost. 2011;106(3):439-447.

12. Guijarro R, Trujillo-Santos J, Bernal-Lopez MR, et al. Trend and seasonality in hospitalizations for pulmonary embolism: a time-series analysis. J Thromb Haemost. 2015;13(1):23-30.

13. Zöller B, Li X, Ohlsson H, Sundquist J, Sundquist K. Age-and sexspecific seasonal variation of venous thromboembolism in patients with and without family history: a nationwide family study in Sweden. Thromb Haemost. 2013;110(6):1164-1171.

14. Donaldson GC, Wedzicha JA. The causes and consequences of seasonal variation in COPD exacerbations. Int J Chron Obstruct Pulmon Dis. 2014;9:1101-1110.

15. Almagro $P$, Hernandez C, Martinez-Cambor P, Tresserras R, Escarrabill J. Seasonality, ambient temperatures and hospitalizations for acute exacerbation of COPD: a population-based study in a metropolitan area. Int J Chron Obstruct Pulmon Dis. 2015;10:899-908.

16. Williams NP, Coombs NA, Johnson MJ, et al. Seasonality, risk factors and burden of community-acquired pneumonia in COPD patients: a population database study using linked health care records. Int JChron Obstruct Pulmon Dis. 2017;12:313-322.

17. Cheng Y, Han X, Luo Y, Xu W. Deaths of obstructive lung disease in the Yangpu district of Shanghai from 2003 through 2011: a multiple cause analysis. Chin Med J (Engl). 2014;127(9):1619-1625.

18. Jenkins CR, Celli B, Anderson JA, et al. Seasonality and determinants of moderate and severe COPD exacerbations in the TORCH study. Eur Respir J. 2012;39(1):38-45.

19. Rabe KF, Fabbri LM, Vogelmeier C, et al. Seasonal distribution of COPD exacerbations in the Prevention of Exacerbations with Tiotropium in COPD trial. Chest. 2013;143(3):711-719.

20. Miravitlles M, Ferrer M, Pont A, et al. Effect of exacerbations on quality of life in patients with chronic obstructive pulmonary disease: a 2 year follow up study. Thorax. 2004;59(5):387-395.

21. Wilkinson TMA, Aris E, Bourne S, et al. A prospective, observational cohort study of the seasonal dynamics of airway pathogens in the aetiology of exacerbations in COPD. Thorax. 2017;72(10):919-927. 
22. Wise RA, Anzueto A, Calverley P, et al. The Tiotropium Safety and Performance in Respimat Trial (TIOSPIR), a large scale, randomized, controlled, parallel-group trial-design and rationale. Respir Res. 2013; 14:40.

23. Wise RA, Anzueto A, Cotton D, et al. Tiotropium respimat inhaler and the risk of death in COPD. N Engl J Med. 2013;369(16):1491-1501.

24. McGarvey LP, Magder S, Burkhart D, et al. Cause-specific mortality adjudication in the UPLIFT ${ }^{\circledR}$ COPD trial: findings and recommendations. Respir Med. 2012;106(4):515-521.

25. Wise RA, Kowey PR, Austen G, et al. Discordance in investigatorreported and adjudicated sudden death in TIOSPIR. ERJ Open Res. 2017;3(1):00073-02016.

26. Hurst JR, Donaldson GC, Quint JK, Goldring JJ, Baghai-Ravary R, Wedzicha JA. Temporal clustering of exacerbations in chronic obstructive pulmonary disease. Am J Respir Crit Care Med. 2009;179(5): 369-374.
27. Suissa S, Dell'Aniello S, Ernst P. Long-term natural history of chronic obstructive pulmonary disease: severe exacerbations and mortality. Thorax. 2012;67(11):957-963.

28. Drummond MB, Wise RA, John M, Zvarich MT, McGarvey LP. Accuracy of death certificates in COPD: analysis from the TORCH trial. COPD. 2010;7(3):179-185.

29. Wise R, Anzueto A, Dahl R, Dusser D, Calverley P. Tiotropium safety in 'real-world' populations: response to Schmiedl, et al. in the British Journal of Clinical Pharmacology. Br J Clin Pharmacol. 2016;82(2): $562-563$.

30. Make B, Dutro MP, Paulose-Ram R, Marton JP, Mapel DW. Undertreatment of COPD: a retrospective analysis of US managed care and Medicare patients. Int J Chron Obstruct Pulmon Dis. 2012;7: $1-9$.

31. Wedzicha JA, Singh R, Mackay AJ. Acute COPD exacerbations. Clin Chest Med. 2014;35(1):157-163.

\section{Publish your work in this journal}

The International Journal of COPD is an international, peer-reviewed journal of therapeutics and pharmacology focusing on concise rapid reporting of clinical studies and reviews in COPD. Special focus is given to the pathophysiological processes underlying the disease, intervention programs, patient focused education, and self management protocols.

\section{Dovepress}

This journal is indexed on PubMed Central, MedLine and CAS. The manuscript management system is completely online and includes a very quick and fair peer-review system, which is all easy to use. Visit $\mathrm{http}: / / \mathrm{www}$. dovepress.com/testimonials.php to read real quotes from published authors.

Submit your manuscript here: http://www.dovepress.com/international-journal-of-chronic-obstructive-pulmonary-disease-journal 